\title{
USO DO SILO DE PLÁSTICO ASSOCIADO À SUTURA ELÁSTICA NO FECHAMENTO DE FERIDA
}

\author{
Rui Lopes Filho ${ }^{1}$ \\ Lucas Carvalho Lopes ${ }^{2}$
}

RESUMO: Introdução: O fechamento de feridas em áreas de difícil confecção de retalhos é um desafio ao cirurgião. Objetivo: apresentar o uso de silo de plástico com sutura elástica no fechamento de ferida. Método: Realizou-se o descolamento dos retalhos cutâneos a partir das bordas da ferida, sendo o silo de plástico (bolsa de Bogotá) disposto sob as bordas da ferida. O elástico usado para a tração foi obtido a partir da extremidade correspondente ao punho da luva cirúrgica. A fixação do elástico na pele das bordas da ferida foi realizada, por meio de pontos com fio mononylon 3.o. Resultado: Após 48 horas do término do procedimento, foi possível o fechamento da ferida. Conclusão: A utilização da técnica proposta permitiu o deslizamento dos retalhos da ferida sobre o silo de plástico, promovido pela tração elástica, possibilitando o fechamento mais rápido da ferida.

Descritores: Suturas. Ferimentos e Lesões. Resistência à Tração. Cirurgia. Cirurgia Plástica.

\section{INTRODUÇÃO}

O tratamento de feridas extensas em áreas de difícil confecção de retalhos é um grande desafio para o cirurgião'. A sutura da ferida utilizando elásticos estéreis foi utilizada, inicialmente, evitando fechamentos da ferida com tensão e a necessidade de

\footnotetext{
'Doutor e Mestre em Cirurgia pela Faculdade de Medicina da Universidade Federal de Minas Gerais. Graduado em Medicina pela Faculdade de Ciências Médicas de Minas Gerais. Cirurgião Plástico Membro Titular e Especialista da Sociedade Brasileira de Cirurgia Plástica. Membro Especialista em Cirurgia Plástica pelo Hospital das Clínicas MEC UFMG. Docente Professor da Faculdade de Medicina da Universidade Federal de Minas Gerais no período de 2006-2009. Médico Legista Classe Especial da Polícia Civil de Minas Gerais. ORCID: https://orcid.org/oooo-ooo2-1627-9371. E-mail: ruilopesfilho@terra.com.br.

${ }^{2}$ Aluno da Graduação em Medicina da Faculdade de Ciências Médicas de Minas Gerais. Cursos realizados: Suporte Básico de Vida Infomedics Human Biology Explained. Atualizações em Suporte Ventilatório Faculdade Inspirar. Novas Plataformas Robóticas Unicetrex Cursos Médicos. Robô da Vinci SP - Experiências e Resultados de um Centro de Referência Unicetrex Cursos Médicos. Neuroimagem Centro de Treinamento em Diagnóstico por Imagem. Anatomia e Patologia dos MMSS por Imagem Centro de Treinamento em Diagnóstico por Imagem. Anatomia e Patologia do Abdome por Imagem Centro de Treinamento em Diagnóstico por Imagem. E-mail: carvalholopesl@gmail.com. ORCID: https://orcid.org/oooo-oooz-0445-1330.E-mail: carvalholopesl@gmail.com.br.
} 
enxertos cutâneos ${ }^{2}$. O silo de plástico ou bolsa de Bogotá é, habitualmente, utilizada para o controle de danos no abdome agudo com sepse associada, o que possibilita importante recurso ao cirurgião, permitindo explorações e lavagens da cavidade de forma facilitada $3,4,5$. O objetivo do estudo é apresentar a utilização do silo de plástico associado com a sutura elástica no fechamento de ferida.

\section{Método}

Realizou-se, inicialmente, o descolamento dos retalhos cutâneos, a partir das bordas da ferida. O silo de plástico (bolsa de Bogotá) foi disposto sob as bordas da ferida (Figura I).

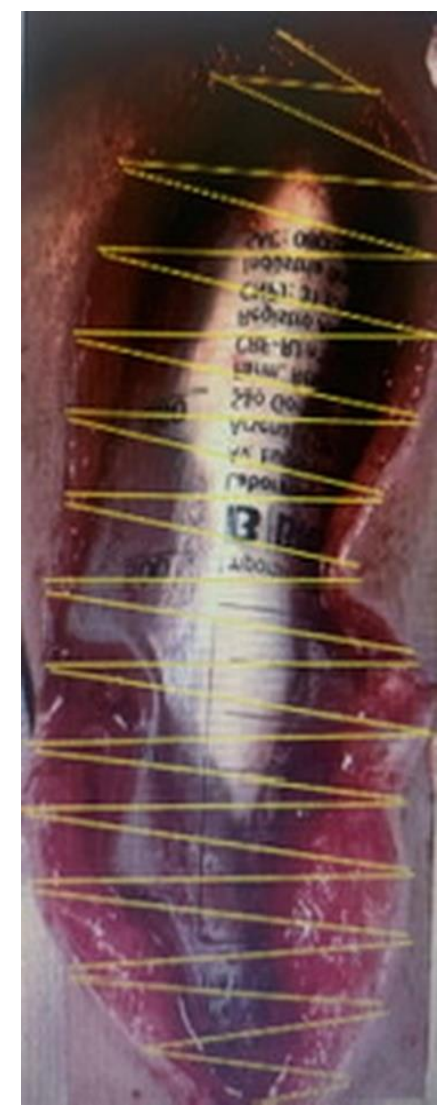

Figura I: Sutura elástica aplicada nas bordas da ferida. Silo de plástico disposto sob as bordas ao fundo.

O elástico usado para a tração foi obtido a partir da extremidade do punho da luva cirúrgica, sendo a fixação do elástico na pele das bordas da ferida realizada, por 
meio de pontos com fio mononylon 3.0 (Figura 2). Após 48 horas do término do procedimento descrito, realizou-se a sutura da ferida, finalizando o tratamento.

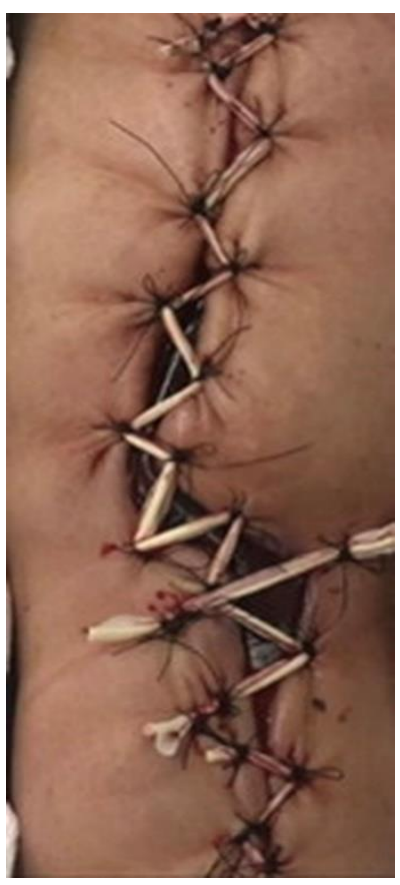

Figura 2: Tração elástica com aproximação das bordas e fechamento da ferida em 48 horas.

\section{Resultado}

A utilização da técnica proposta permitiu o deslizamento dos retalhos das bordas da ferida sobre o silo de plástico, sendo promovida pela tração elástica, possibilitando o fechamento da ferida em 48 horas.

\section{Discussão}

O silo de plástico é composto de plástico fino e resistente, sendo utilizada amplamente na cirurgia geral para confecção da bolsa de Bogotá, em protocolo de tratamento e controle de danos no abdome agudo cirúrgico, nos pacientes com sepse ${ }^{3,4,5}$. O elástico confeccionado a partir da extremidade do punho da luva cirúrgica, utilizado para a realização da sutura elástica, constitui-se de material estéril, prontamente disponível no bloco cirúrgico, que apresenta propriedades de tensão, resistência e resiliência adequados para a realização da sutura elástica. A técnica cirúrgica que utiliza o fechamento de feridas por tração ${ }^{6,7}$ tem sido utilizada com bons resultados ${ }^{8,9,10}$. Entretanto, o uso do silo de plástico (bolsa de Bogotá) associado com a sutura elástica é um recurso que proporciona um melhor deslizamento das bordas da ferida, possibilitando o fechamento mais rápido da ferida, no período de 48 horas.

\section{Conclusão}


A utilização do silo de plástico (bolsa de Bogotá) associado com a sutura elástica possibilitou o deslizamento dos retalhos descolados e o fechamento da ferida no período de 48 horas.

\section{Referências}

I.Santos ELN, Oliveira RA. Sutura elástica para tratamento de grandes feridas. Rev Bras Cir Plást. 2012;27(3):475-7.

2.Petroianu A. Síntese de grandes feridas daparede corpórea com tira elástica de borracha. ABCD Arq Bras Cir Dig. 2010;23(I):16-8.

3. Torres Neto JR, Barreto AP, Prudente ACL, Santos AM, Santiago RR. Uso da Peritoneostomia na sepse abdominal. Rev bras Coloproct, 2007;27(3): 278-283.

4. Howdieshell T R, Proctor C D, Sternberg E, Cue J I, Mondy J S, Hawkins M L. Temporary abdominal closure followed by definitive abdominal wall reconstruction of the open abdomen. Am J of Surg 2004; 188: p 30I-306.

5.Drumond DAF. Fechamento de laparostomia com descolamento cutâneo-adiposo: uma técnica simples e eficaz para um problema complexo. Rev Col Bras Cir, 2010;37(3):175-183.

6.Armstrong DG, Sorensen JC, Bushman TR. Exploiting the viscoelastic properties of pedal skin with the sure closure skin stretching device. J Foot Ankle Surg. 1995;34:247- 253 .

7.Gibson T, Kenedi RM. Biochemical properties of skin. Surg Clin North Am. 1967;47:279-294.

8.Hussain SH, Limthongkul B, Humphreys TR. The biomechanical properties of the skin. Dermatol Surg. 2013;39:193-203.

9.Wilhelmi BJ, Blackwell SJ, Mancoll JS, Phillips LG. Creep vs. stretch: A review of the viscoelastic properties of skin. Ann Plast Surg. 1998;41:215-219.

Io.Liang MD, Briggs P, Heckler FR, Futrell JW. Presuturing-a new technique for closing large skin defects: Clinical and experimental studies. Plast Reconstr Surg. 1988;81:694- 702. 